\title{
Profile of Helicobacter pylori cytotoxin derived from two areas of Japan with different prevalence of atrophic gastritis
}

\author{
S Ito, T Azuma, H Murakita, M Hirai, H Miyaji, Y Ito, Y Ohtaki, Y Yamazaki, \\ M Kuriyama, Y Keida, Y Kohli
}

\begin{abstract}
Background and Aim-To clarify the roles of Helicobacter pylori cytotoxin in gastric atrophy, the cytotoxin positive rate and cytotoxin activity in Fukui and Okinawa, where the prevalence of atrophic gastritis and gastric cancer risk are quite different, were studied.
\end{abstract}

Materials-Seventy three strains from Fukui and 51 from Okinawa were examined.

Methods-The validation of atrophy was done by endoscopy, being confirmed with histology. The supernatant of liquid $H$ pylori culture media was concentrated 20-fold, serially diluted, using doubling dilutions, and scored from 1 to 8 . The semi-quantitated cytotoxin activity was expressed as the maximum dilution score yielding $>50 \%$ A431 cell vacuolation, being standardised with bacterial density.

Results-The cytotoxin activity of the strains from Fukui was highly diverse compared with that from Okinawa, although the cytotoxin positive rate was not different. In Fukui strains, the grade of atrophy and the cytotoxin activity were correlated $(p<0.05)$. In addition, the cytotoxin activity of the strains from all patients in Okinawa, most of whom showed closed-type/mild atrophy, was significantly lower than that of the strains from the patients with open-type/severe atrophy in Fukui (6.46 (5.53) v 9.76 (8.80), p<0.05), (mean (SEM)).

Conclusion-The difference in profile of the cytotoxin activity in the two areas was related to the difference in the prevalance of atrophic gastritis.

(Gut 1996; 39: 800-806)

Keywords: Helicobacter pylori, vacuolating cytotoxin, gastric atrophy.

Division of Interna Medicine, Okinawa Chubu Hospital, Okinawa, Japan Y Keida

Division of Internal Medicine,

Aiseikai-Yamashina

Hospital, Kyoto, Japan

Y Kohli

Correspondence to:

Dr S Ito,

2nd Department of Interna

Medicine, Fukui Medical

School, 23-3, Shimoaizuki,

Matsuoka-cho, Yoshida-gun,

Fukui, 910-11, Japan.

Accepted for publication

8 July 1996

Although the incidence and the death rate of gastric adenocarcinoma in Japan is high compared with that in other developed countries, ${ }^{1}$ large intracountry differences in the death rates of gastric cancer have been reported. ${ }^{2}{ }^{3}$ The death rate in Okinawa prefecture is lower than that in any other prefecture in Japan, including Fukui prefecture. In addition, the prevalence of atrophic gastritis in Okinawa is also significantly lower than that in any other prefecture in Japan. ${ }^{34}$ Although the precise mechanism underlying the development of atrophic gas- tritis and gastric carcinoma is not known, the epidemiology of gastric cancers suggests that environmental agents are important aetiological factors. ${ }^{5}$

Helicobacter pylori is a spiral shaped Gram negative bacterium that is strongly associated with chronic superficial gastritis. ${ }^{6}$ As has been reported elsewhere, ${ }^{7} \mathrm{H}$ pylori infection in Japan has been associated with chronic atrophic gastritis and intestinal metaplasia, the precursor lesions for gastric carcinoma. ${ }^{89}$ In addition, there is increasing evidence that persistent infection with $H$ pylori is a risk factor for the development of gastric cancer, especially of the distal stomach. ${ }^{10-13}$

As not all persons infected with $H$ pylori develop gastric cancer, other cofactors must also be important. Such factors could be host related, bacterium related or related to other environmental factors. In terms of bacterium related factors, $H$ pylori strains are highly diverse. ${ }^{14} 15$ Thus, it is appropriate to isolate particular characteristics of $H$ pylori strains that might affect the risk of gastric cancer development. Recent studies have suggested that $\operatorname{cag} A$, which is closely associated with vacuolating cytotoxin, may be an important factor for the risk of developing adenocarcinoma of the stomach. ${ }^{16}$ Furthermore, the neutralising activity against vacuolating cytotoxin is observed more frequently in serum samples from gastric carcinoma patients than from healthy subjects. ${ }^{17}$

In this study, we determined the differences in the presence of vacuolating cytotoxin and its intensity between the strains derived from the patients in Fukui and Okinawa prefectures, in which the prevalence of atrophic gastritis and the gastric cancer risk were quite different, to clarify their roles in the development of gastric atrophy or the increase in gastric cancer risk, or both.

\section{Methods}

\section{Patients}

The subjects were new patients who were examined for $H$ pylori status by endoscopy in the Second Department of Internal Medicine, Fukui Medical School in Fukui, the middle part of Japan, between February and November 1994 and Okinawa Chubu Hospital in Okinawa, the most south west part of Japan, between September and December 1994. However, nine of 123 examined patients in Fukui and eight of 106 in Okinawa had various diseases other than gastritis or peptic ulcer, that 
is, two with gastric polyp, three with gastric cancer, and four with remnant stomach in Fukui and four with gastric polyp, one with gastric cancer, and three with remnant stomach in Okinawa, and were excluded. The subjects had not been receiving any antisecretory agents or anti- $H$ pylori treatment in the long term before this study. Seventy three of 114 subjects in Fukui (male/female: 45/28) and 51 of 98 subjects in Okinawa (male/female: $24 / 27$ ) were $H$ pylori positive. In Fukui, 41 patients had mild epigastralgia but no gross findings or diseases in their stomach, that is, had only type B gastritis including erosive or superficial gastritis, or both, six with gastric ulcer, and 26 with duodenal ulcer. Similarly in Okinawa, 33 had gastritis, nine gastric ulcer, and nine duodenal ulcer. The duodenal and gastric ulcer patients also had gastritis. The diagnosis was confirmed endoscopically by two endoscopists. The mean (SD) age of the patients in Fukui and Okinawa was $55.5(15.4)$ (range, 16-87) years old and $61 \cdot 0(12 \cdot 1)$ (range, 35-88) years old, respectively. Although the percentage of duodenal ulcer patients in Fukui seemed to be high, the differences in patients found to have ulcers (43.8\% in Fukui $v 35.3 \%$ in Okinawa), the degree of symptoms in the two prefectures was not significantly different.

\section{Validation of atrophy}

Firstly, histological atrophy was examined in 84 of 124 biopsied samples of the antrum with haematoxylin and eosin staining from both prefectures ( 33 from Fukui and 51 from Okinawa) according to the Sydney system, ${ }^{18}$ scored 0 ; none, 1; mild, 2; moderate and 3; severe and compared with endoscopically diagnosed atrophy as described below. Secondly, in all cases, with the location of the endoscopic atrophic border identified by endoscopy, the grade of atrophy was diagnosed according to the criteria of Kimura and Takemoto as reported previously (Fig 1). ${ }^{919-21}$ The endoscopic atrophic border marks the furthest front of the extent of atrophic gastritis from the antrum to the body in the stomach as a result of chronic type $\mathbf{B}$ gastritis, although gastritis may be localised to the antrum in Western patients. ${ }^{21-23}$ In brief, by identifying the location of the endoscopic atrophic border in the stomach, the grade of atrophy was divided into two types, closed-type/mild extension of atrophy and open-type/severely extended atrophy. If the border was on the lesser curvature of the stomach, it was defined as closed-type (C-type). They were subdivided into $\mathrm{C} 1, \mathrm{C} 2$, and $\mathrm{C} 3$ patterns. If the border was shifted orally and did not exist on the lesser curvature, it was defined as open-type (O-type), and subdivided into $\mathrm{O} 1, \mathrm{O} 2$, and $\mathrm{O} 3$ patterns. Therefore, the gastric atrophy was graded as $\mathrm{C} 1, \mathrm{C} 2, \mathrm{C} 3, \mathrm{O} 1$, $\mathrm{O} 2$, and $\mathrm{O} 3$ according to their severity (Fig 1 ).

Preparation of the strains

Gastric biopsy samples were taken from the lesser curvature of the antrum and large curvature of the body of all patients described above using a sterilised endoscope, put into Cary-Blair-N transport medium (Nissui Seiyaku Co. Tokyo, Japan), and cultured on Trypticase Soy Agar-II with 5\% sheep blood (TSA-II) plate (Nippon Bekton Dickinson, Tokyo, Japan) in the microaerophilic condition $\left(\mathrm{O}_{2}: 5 \%, \mathrm{CO}_{2}: 15 \%, \mathrm{~N}_{2}: 80 \%\right)$ for five days. The specimens obtained from Okinawa prefecture were sent by air in the same transport medium in an ice box and cultured within 24 hours after biopsy. In addition, a histological study with Giemsa staining was done on the samples from Okinawa prefecture and confirmed by successful isolation of culture regardless of transport by air. $H$ pylori was identified as Gram negative bacilli with urease, catalase, and oxidase activity. A few colonies of the third cultured $H$ pylori isolates (approximately $10^{5}$ $\mathrm{cfu} / \mathrm{ml}$ ) on a TSA-II plate, which had been well adapted in the in vitro environment, were then cultured in $20 \mathrm{ml}$ of Brucella broth supplemented with $10 \%$ fetal calf serum. Broth cultures were incubated with a gyratory shaker at $120 \mathrm{rpm}$ in a microaerophilic condition for three days. The growth of $H$ pylori was assessed by comparison of the optical density at $560 \mathrm{~nm}$ of the broth culture medium of each $H$ pylori isolate with that of the culture medium alone.

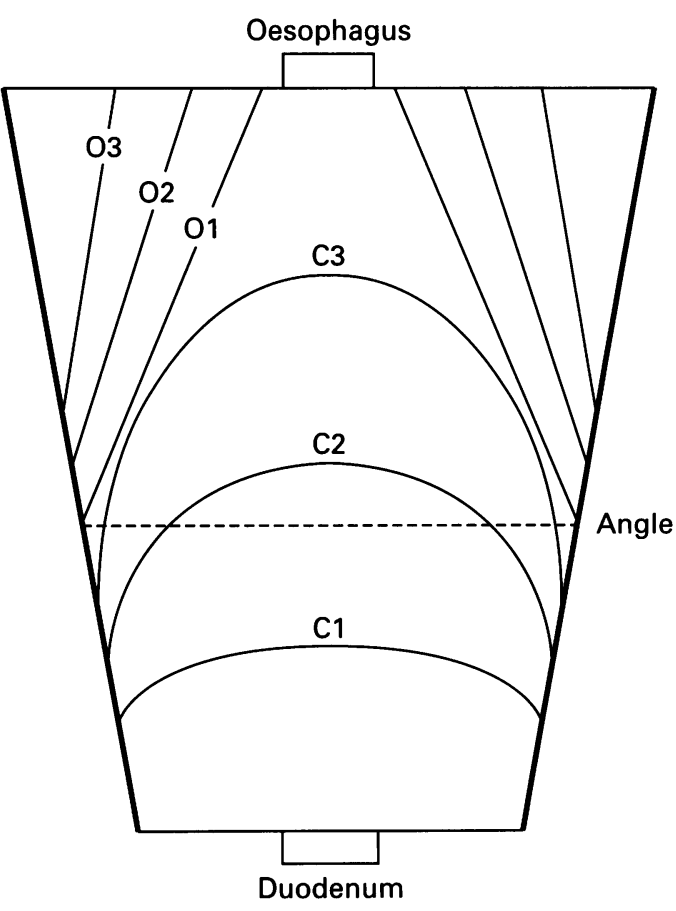

Figure 1: The extension of endoscopic atrophic border and patterns of endoscopically diagnosed atrophic gastritis by Kimura and Takemoto. The endoscopic atrophic border marks the furthest front of the extent of atrophic gastritis in the stomach as a result of chronic type $B$ gastritis in fapanese patients. Fapanese patients tended to have large areas of atrophy and intestinal metaplasia in the stomach. By identifying the location of the endoscopic atrophic border in the stomach, the grade of atrophy was divided into two types, closed-type/mild extension of atrophy and open-type/ severely extended atrophy. If the border was on the lesser curvature of the stomach, it was defined as closed-type (C-type). They were subdivided into $C 1, C 2$, and $C 3$ patterns. If the border was shifted orally and did not exist on the lesser curvature, it was defined as open-type (O-type), and subdivided into $\mathrm{O} 1, \mathrm{O} 2$, and $\mathrm{O} 3$ patterns. Therefore, the gastric atrophy was graded as C1, C2, C3, O1, O2, and $\mathrm{O} 3$ according to their severity. 
Evaluation of cytotoxin production and quantification of activity

A431 (ATCC CRL 1555) cells were derived from human squamous cell carcinoma and kindly provided by Dr Shimizu (Keio University, Tokyo, Japan). Cells were maintained as described previously. ${ }^{24}$ A431 cells $\left(0.2 \times 10^{4}\right.$ cells) were inoculated into each well of a 96 well microtitre plate. After a 24 hour incubation period, the medium was replaced with $90 \mu \mathrm{l}$ of fresh medium supplemented with 10 $\mathrm{mmol} / \mathrm{l}$ ammonium chloride to potentiate cytotoxin activity. The supernatant of $H$ pylori culture was concentrated 20 -fold by using a $100 \mathrm{kDa}$ ultrafiltration membrane (Ultrafree C3HK, Millipore, Maryland, USA) and then sterilised by passage through a $0.22 \mu \mathrm{m}$ filter (Ultrafree C3GV, Millipore, Maryland, USA). For determination of the relative cytotoxin activity, the concentrated culture supernatants were serially diluted, using doubling dilutions of $1,2,4,8,16,32,64$, and 128 by the $A 431$ culture medium and scored from 1 to 8 . Ten $\mu l$ of aliquot was added to $90 \mu \mathrm{l}$ of A431 medium in a 96 well plate. After a 24 hour incubation period, cells were examined microscopically for the presence of intracellular vacuolisation. The relative cytotoxin activity was expressed as the maximum dilution score yielding $>50 \%$ A431 cell vacuolation. The relative activity was defined as 0.5 in a sample of score 1 supernatant that showed vacuolation in less than $50 \%$ of the cells. For standardisation by bacterial number, the semi-quantitated cytotoxin activity was expressed by dividing the relative activity with each remainder of optical density between a 3 day old liquid culture of $H$ pylori and culture medium alone.

We compared the positive rate of $H$ pylori cytotoxin and their intensity in all patients and in the patients with gastritis alone between two prefectures. Then, an age matched study was

TABLE I Examined patients in Fukui and Okinawa and their cytotoxin positive rate

\begin{tabular}{lllll}
\hline & Gastritis & Gastric ulcer & Duodenal ulcer & Total \\
\hline Examined cases in Fukui & 78 & 8 & 28 & 114 \\
H pylori positive cases & 41 & 6 & 26 & 73 \\
Cytotoxin positive cases & 31 & 5 & 14 & 50 \\
Cytotoxin positive rate (\%) & $75 \cdot 6$ & $83 \cdot 3$ & $53 \cdot 8$ & $57 \cdot 5$ \\
Examined cases in Okinawa & 77 & 10 & 11 & 98 \\
H pylori positive cases & 33 & 9 & 9 & 51 \\
Cytotoxin positive cases & 24 & 4 & 6 & 34 \\
Cytotoxin positive rate (\%) & $72 \cdot 7$ & $44 \cdot 4$ & $66 \cdot 7$ & $66 \cdot 7$ \\
\hline
\end{tabular}

The cytotoxin positive rate of the strains in Fukui and Okinawa was not different. In each group, the rate was slightly higher in the strains from atrophic gastritis than from duodenal ulcer. the rastis patients had mild epigastralgia but no gross findings or diseases in their stomach, that is, had only type B gastritis including erosive or superficial gastritis, or both.

TABLE II Cytotoxin positive rate according the decade from age 40 to 79 in Fukui and Okinawa

\begin{tabular}{llllll}
\hline Age & $40-49$ & $50-59$ & $60-69$ & $70-79$ & Total \\
\hline Fukui & 13 & 18 & 17 & 11 & 59 \\
H pylori positive cases & 10 & 13 & 11 & 8 & 42 \\
Cytotoxin positive cases & $76 \cdot 9$ & $72 \cdot 2$ & $64 \cdot 7$ & $72 \cdot 7$ & $71 \cdot 2$ \\
Cytotoxin positive rate (\%) & & & & & \\
$\begin{array}{l}\text { Okinawa } \\
\text { H pylori positive cases }\end{array}$ & 6 & 10 & 20 & 10 & 46 \\
Cytotoxin positive cases & 3 & 8 & 13 & 7 & 31 \\
Cytotoxin positive rate (\%) & $50 \cdot 0$ & $80 \cdot 0$ & $65 \cdot 0$ & $70 \cdot 0$ & $67 \cdot 4$ \\
\hline
\end{tabular}

The cytotoxin positive rate of the strains in Fukui and Okinawa was not affected by age from 40 to 79 . performed on those from age 40 to 79 . The cytotoxin positive rate and the intensity were determined for every decade in Fukui and Okinawa.

\section{Statistics}

The cytotoxin positive rate was analysed by the $\chi^{2}$ test. The relation between atrophy diagnosed histologically and endoscopically and that between the grade of gastric atrophy and the degree of cytotoxin activity were analysed by the Spearman rank correlation test. The difference in cytotoxin activity between Fukui and Okinawa was compared by the Student's $t$ test.

\section{Results}

There was no significant difference in the cytotoxin positive rate between Fukui and Okinawa for any of the strains isolated (Table I), or between age groups (Table II), although the number in some age groups was too small for comparison.

The histological atrophy of the antrum and the endoscopically diagnosed atrophy were positively correlated according to the Spearman rank correlation test (Fig 2$)(\mathrm{p}<0 \cdot 01)$.

The semi-quantitated cytotoxin activity of the strains from Fukui was highly diverse compared with that of Okinawa (Fig 3). In Fukui strains, there was a positive correlation between the grade of endoscopically diagnosed gastric atrophy and the cytotoxin activity

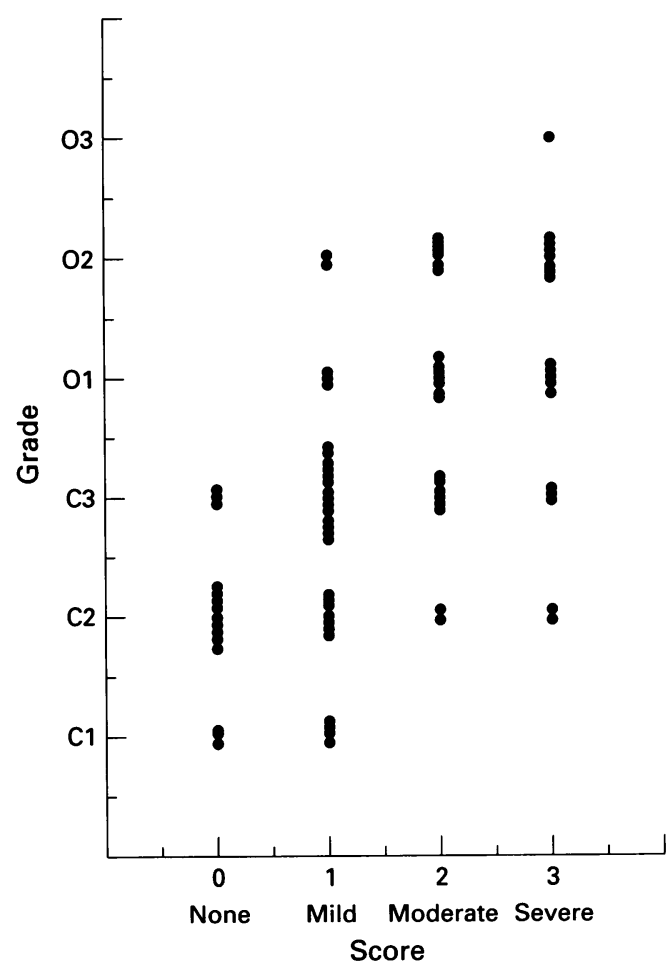

Figure 2: Correlation between histological atrophy of the antrum and endoscopically diagnosed atrophy. They had a positive correlation $(p<0.01)$. The $x$ axis is histological atrophy according to the Sydney system and the $y$ axis is endoscopically diagnosed atrophy according to the criteria of Kimura and Takemoto. The histological atrophy was scored as 0 ; none, 1; mild, 2; moderate and 3; severe.

Endoscopically diagnosed atrophy was graded as C1, C2, $\mathrm{C3}, \mathrm{O1}, \mathrm{O2}$, and $\mathrm{O} 3$ according to their severity. 

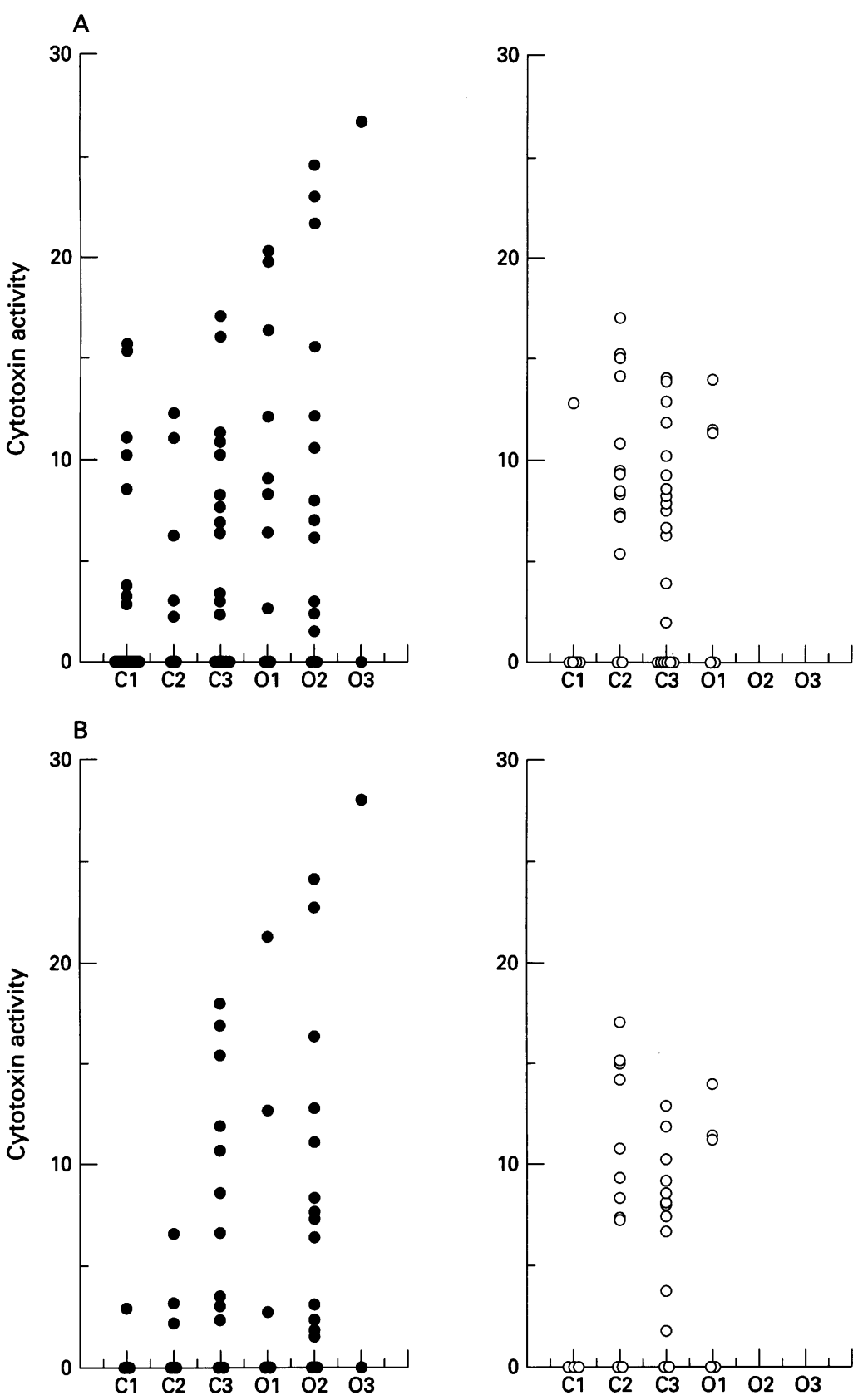

Figure 3: Correlation between the grade of gastric atrophy and the intensity of cytotoxin activity of isolated $\mathrm{H}$ pylori $(A)$ in all patients examined and $(B)$ in the patients with gastritis alone in Fukui (O) and Okinawa (O). The cytotoxin activity of isolated $\mathrm{H}$ pylori was semi-quantitatively described. The grade of atrophy was expressed as C1, C2, C3, O1, $\mathrm{O} 2$, and $\mathrm{O} 3$ according to its severity. The cytotoxin activity was correlated with the endoscopically diagnosed gastric atrophy in all patients $(A)$ and in gastritis alone $(B)$ in Fukui $(p<0.05)$. Most of the patients in Okinawa had closed-type/mild atrophy. The cytotoxin activity (mean (SEM)) of all the strains from Okinawa was significantly lower than that from the patients with open-type/severe atrophy in Fukui (6.46 (5.53) v 9.76 $(8.80), p<0.05)$.
When age matched for every decade, a similar finding was clearly observed for those over 60 years old (Figs 4 and 5). The cytotoxin activity was more diverse in Fukui than in Okinawa, correlated with the grade of atrophy. The cytotoxin activity from the patients with open-type/severe atrophy in Fukui was higher than that of all strains in Okinawa.

\section{Discussion}

In this study, the cytotoxin activity of $H$ pylori strains isolated from Fukui was highly diverse compared with that of the strains from Okinawa. The intensity of the cytotoxin activity in Fukui had a positive correlation with the degree of gastric atrophy when examined in all 73 cases and in 41 cases of gastritis alone $(p<0.05)$, especially in those over 60 years old. More virulent strains on the point of cytotoxin production were associated with the patients in Fukui who had open-type/severe atrophy. In contrast, the virulency of the strains from Okinawa was weak and the degree of atrophy was also mild. In several studies, cytotoxin positive strains have been more associated with peptic ulcers, chronic gastritis with severe inflammation and eventually atrophic gastritis. ${ }^{25-27}$ However, the cytotoxin positive rate was not different between Okinawa and Fukui, regardless of the differences in gastric atrophy. This suggested that the intensity of cytotoxin activity was more closely related to the development of gastric atrophy.

Our study showed that endoscopically diagnosed atrophy was correlated with the histological atrophy of the gastric antrum. In many previous works, the endoscopically diagnosed atrophy is reported to be well correlated with the extension of pyloric gland atrophy and intestinal metaplasia and also negatively correlated with the acid output of the stomach. ${ }^{19-22}$ As mentioned above, the endoscopic atrophic border marks the furthest front of the extent of atrophic gastritis in the stomach as a result of chronic type B gastritis in Japanse patients. Japanese patients tended to have a large area of atrophy and intestinal metaplasia in the stomach, although gastritis may be localised to the antrum and there is much more multi-focal atrophic gastritis in the West. ${ }^{21-23} 28$ The Sydney system for the classification of gastritis takes into account the density of $H$ pylori infection, the degree of inflammation, the level of gastritis activity, the grade of atrophy and intestinal metaplasia by the histology, and expressed as the antral/corporal/pan-gastritis. ${ }^{18}$ It is useful for the expression of closed-type/ mild to moderate extension of atrophy (Fig 1). However, a couple of biopsy specimens is not sufficient to clearly subdivide the open-type/ severely extended atrophy in the corpus and fornix, as often observed in Japanese patients. ${ }^{21}$ In this study, therefore, the grade of the extension of the atrophy was diagnosed by endoscopy and compared with the cytotoxin activity. In addition to the patients with gastric ulcer, Japanese patients with duodenal ulcer also had gastritis in the antrum and sometimes atrophy or intestinal metaplasia, or both, Fukui $(6.46(5.53) v 9.76(8.80), \mathrm{p}<0.05)$. In the comparison of strains from the patients with gastritis alone in both prefectures, the tendency was the same, although it was not statistically significant $(7 \cdot 31 \quad(5.58) \quad v \quad 8.87$ (8.75), $\mathrm{p}>0.05)$. 

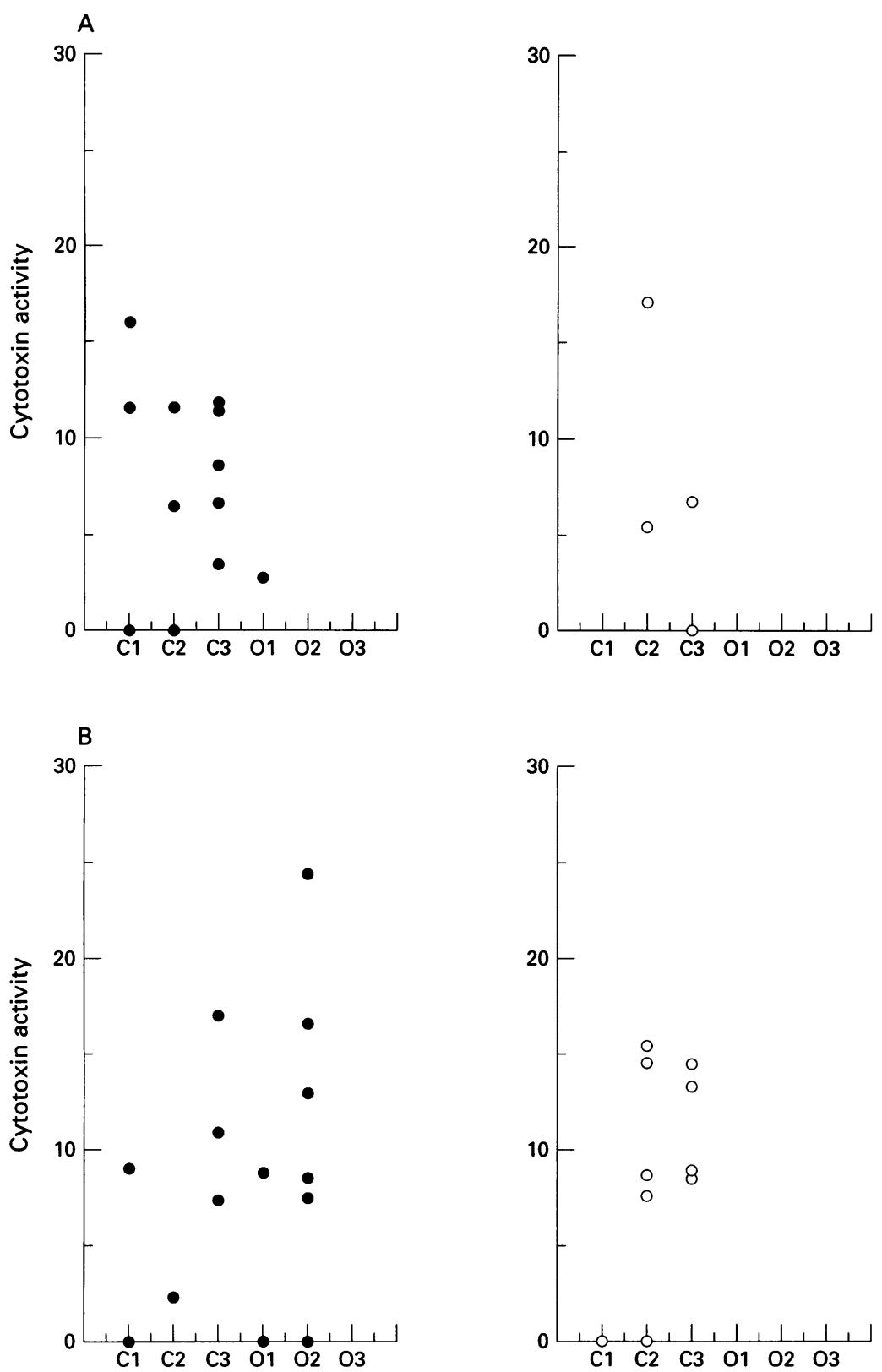

Figure 4: Correlation between the grade of gastric atrophy and the cytotoxin activity of patients in their 40s $(A)$ and 50 s $(B)$ in Fukui $(O)$ and Okinawa $(O)$. The grade of atrophy was expressed as $C 1, C 2, C 3, O 1, O 2$, and $O 3$ according to its severity. Although the cytotoxin activity of the strains from the patients in their 40s showed no difference

between Fukui and Okinawa, that from the patients in their 50s in Fukui was diverse and some of them who had open-type/severe atrophy showed high cytotoxin activity.

although the grade of their atrophy was closedtype/mild. Gastric cancer patients also had duodenal ulcers in about $1 \cdot 2 \%$ of the resected specimens in Japan. ${ }^{29}$ Because, in Japan, almost all patients who had been infected with $H$ pylori may have a risk for the development of atrophy, we compared the gastric atrophy in all patients in addition to the patients with gastritis alone. Extension of atrophic gastritis from the antrum to the corpus probably depends on a number of genetic and environmental factors, including diet, alcohol consumption, bile reflux, and infection with $H$ pylori. Of them, infection with $H$ pylori as well as the intensity of cytotoxin is thought to be a powerful trigger of the extension of gastric atrophy.

Risk factors for atrophic gastritis are also linked to those for gastric cancer, ${ }^{40}$ although more factors and multiple steps are associated with the development of gastric adenocarcinoma. ${ }^{31}$ Recent studies have shown that cytotoxin production does not necessarily require the $\operatorname{cag} A$ gene. ${ }^{32}{ }^{33}$ However, cytotoxin production is associated with $\operatorname{cag} A$ expression. ${ }^{26}{ }^{27} \mathrm{Cag} A$ positive strains were more virulent and more immunologically strong. ${ }^{27}$ In addition, by the serological studies, the antiCagA antibody or neutralising antibody to cytotoxin in their sera were more associated with the risk for gastric cancer. ${ }^{16}{ }^{17}$ As environmental exposure early in life has been implicated in the pathogenesis of gastric cancer, ${ }^{5}$ the exposure to more virulent strains may be correlated with the development of gastric adenocarcinomas. The large difference in the prevalence of atrophic gastritis between Fukui and Okinawa may depend on the difference in the profile of cytotoxin activity of $H$ pylori and may eventually reflect the difference in gastric cancer risk to some degree.

Although the simultaneous gastric infection with two $H$ pylori strains has been reported at frequencies of $10-13 \%,{ }^{15}$ the PCR-RFLP patterns using the ure $B$ locus showed that almost all patients had the same strain throughout their lifetime. ${ }^{34}$ Megraud et $a l^{35}$ reported by the analysis of molecular fingerprinting of $H$ pylori that differences were not due to a change of the strain but to the minor genomic change within the same strain during the long $H$ pylori infection. Therefore, the virulency of the strain was continuously conserved for a long period, albeit with some exceptions. ${ }^{36}$ In addition, divergence of genetic sequences for the vacuolating cytotoxin among $H$ pylori strains has been reported and the variation in the length of the $\operatorname{vac} A$ gene could reflect the phenotype in the strains. ${ }^{37} 38$ Recently, differences in the cytotoxin activity have been also reported and genetically determined..$^{39}$ In addition, cytotoxin activity is also affected by their secretory function, which has been reported to be similar with the IgA protease type of exoprotein. ${ }^{40}$ Further studies are necessary to clarify the mechanism to induce different cytotoxin activity.

$H$ pylori infection is established in childhood. ${ }^{42}$ Several epidemiological studies suggested that the incidence of $H$ pylori infection increases in adolescence in Japan and other developed countries. ${ }^{44}$ Therefore, patients over 60 years old may have been exposed and affected with $H$ pylori infection for more than 20 years. The association between the period of $H$ pylori infection and the development of gastric atrophy has been suggested. ${ }^{11} 124145$ In this study, a positive correlation was seen between gastric atrophy and cytotoxin activity especially in those over 60 years old. Therefore, longer exposure to $H$ pylori infection as well as the exposure to a more virulent factor may be necessary for the development of severe gastric atrophy. Under 60 years old, the difference between Fukui and Okinawa was not so clear, although the examined number of patients under 50 years old was too small to make a comparison. The other reason may be that the strain from the 

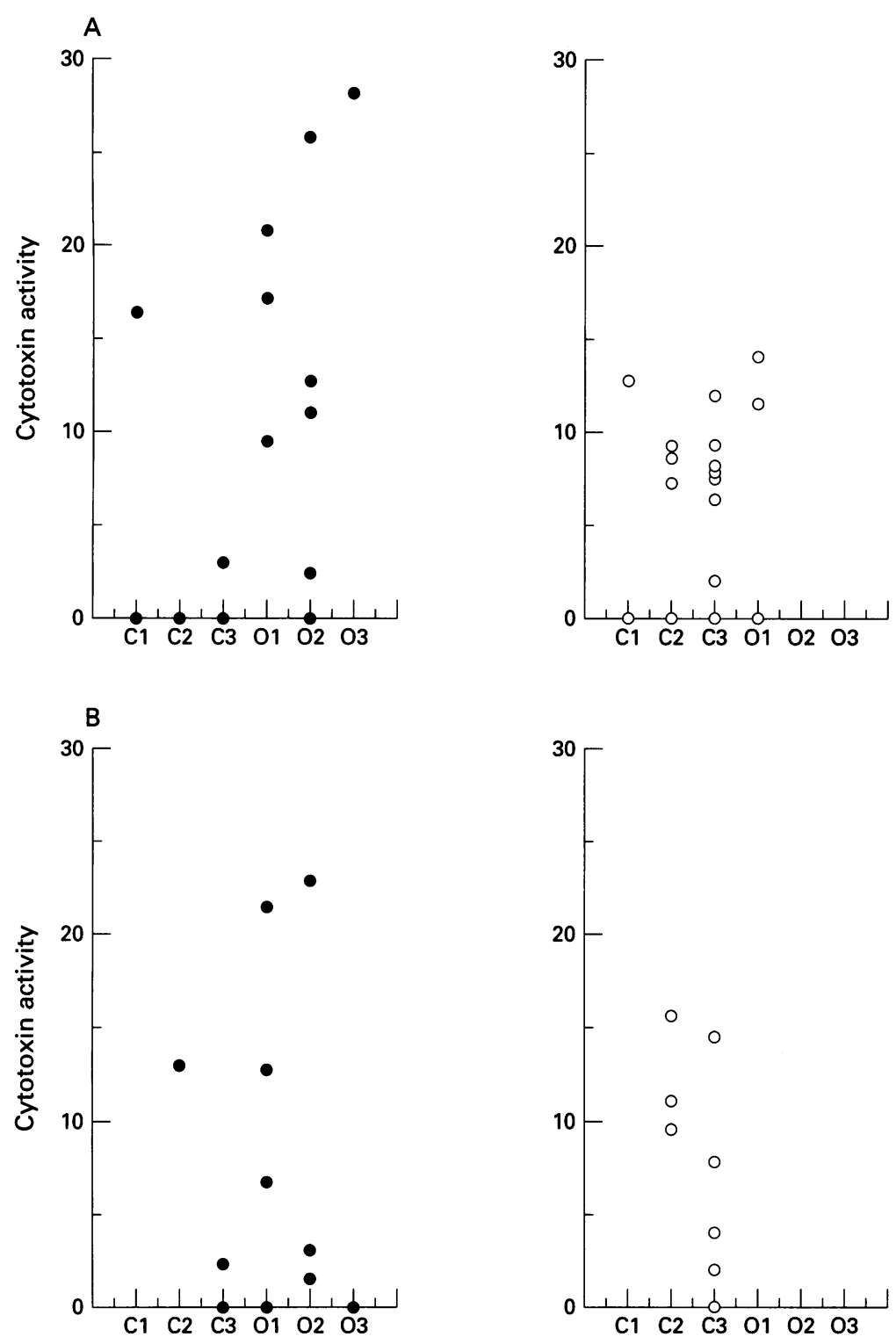

Figure 5: Correlation between the grade of gastric atrophy and the cytotoxin activity of patients who were in their $60 \mathrm{~s}(A)$ and $70 \mathrm{~s}(B)$ in Fukui $(O)$ and Okinawa $(O)$. The grade of atrophy was expressed as C1, C2, C3, O1, O2, and O3 according to its severity. The cytotoxin activity of the strains from the patients in their 60s in Fukui was highly diverse and correlated significantly with the grade of atrophy $(p<0.05)$. On the contrary, that from Okinawa showed relatively low activity.

younger generation in Okinawa is changing and likely to have a strong cytotoxin activity. A longer chronological study on a younger generation will be needed to clarify this problem.

In Okinawa prefecture, the prevalence of $H$ pylori infection has been reported to be lower than that in other prefectures in Japan. ${ }^{3} \mathrm{We}$ also obtained a similar finding in this study, although the difference was not significant $(52.0 \% v 64.0 \%, \mathrm{p}>0.05)$. The prevalence of atrophic gastritis and the death rate of gastric cancer were also significantly lower than in other prefectures in Japan. ${ }^{2-4}$ Many epidemiological studies suggested a correlation between the prevalence of $H$ pylor $i$ infection and the risk of gastric cancer. ${ }^{10-134647}$ However, several intracountry analyses failed to show any association between gastric cancer risk and $H$ pylori infection. ${ }^{48} 49$ Various factors are involved in the development of gastric atrophy or gastric cancer, or both. In terms of $H$ pylori infection, not only the prevalence of $H$ pylori infection and the analysis of cytotoxin positive rate but also the analysis of the virulency in cytotoxin activity will be needed to clarify the association between $H$ pylori infection and gastric cancer risk.

In contrast, the fact that the strains without cytotoxin activity or with lower cytotoxin activity in Fukui were also found in patients with severe atrophic gastritis showed that factors others than $H$ pylori cytotoxin might also be responsible for atrophic gastritis. Many pathogenic factors of $H$ pylori strains have been reported. ${ }^{6}$ Differences in the host or in the host strain relation have also been suggested as a cause of the difference in the prevalence of atrophic gastritis and the death rate of gastric cancer between Fukui and Okinawa. ${ }^{50} 51$ Food and life style may also affect the development of gastric carcinoma and the difference in death rate. $^{331}$ The HLA-DQA gene is a candidate gene for the host's susceptibility in the establishment of $H$ pylori infection and the development of gastric atrophy. ${ }^{52}{ }^{53}$ The Leb+ antigen is one of the factors for the attachment of $H$ pylori infection..$^{54} \mathrm{We}$ are now studying these factors in Fukui and Okinawa.

In conclusion, the cytotoxin activity observed in Fukui strains was highly diverse and was correlated with the development of gastric atrophy. The difference in profile of the cytotoxin activity in Fukui and Okinawa was related to the difference in the prevalence of atrophic gastritis, which eventually may reflect the difference in the gastric cancer risk between them.

1 Watanabe S, Arimoto $\mathrm{H}$. Long term trends in cancer mortality rates and cumulative rates from 1955 to 1987 mortality rates and cumulative rates from 1955

2 Statistics and Information Department, Minister's Secretariat. Vital Statistics of fapan. Tokyo: Ministry of Health and Welfare, 1992 (in Japanese).

3 Tsugane S, Kabuto M, Imai H, Gey F, Tei Y, Hanaoka T, et al. Helicobacter pylori, dietary factors and atrophic gastritis in five Japanese populations with different gastric cancer mortality. Cancer Causes Control 1993; 4: 297-305.

4 Kabuto M, Imai H, Tsugane S, Watanabe S. Correlation between atrophic gastritis prevalence and gastric cancer mortality among middle-aged men in 5 areas in Japan. $f$ Epidemiol 1993; 3: 35-9.

5 Howson CP, Hiyama T, Wynder EL. The decline in gastric cancer: epidemiology of an unplanned triumph. Epidemiol $\operatorname{Rev} 1986 ; 8: 1-27$.

6 Blaser MJ. Helicobacter pylori and the pathogenesis of gastroduodenal inflammation. F Infect Dis 1990; 161: 626-33.

7 Craanen ME, Dekker W, Blok P, Ferwerda J, Tytgat GNJ. Intestinal metaplasia and Helicobacter pylori: an endoscopic bioptic study of the gastric antrum. Gut 1992; 33: $16-20$.

8 Sakaki N, Momma K, Yamada Y, Tadokoro Y, Tajima T. Helicobacter pylori infection and the development of atrophic gastritis assessed by endoscopy. Eur 7 Gastroenterol Hepatol 1992; 4: 585-7.

9 Kohli Y, Kato T, Iwaki M, Ito S, Suzuki K. Endoscopic diagnosis of Helicobacter pylori distribution in gastric mucosa of patients with chronic gastritis. Eur $₹$ Gastromucosa of patients with chronic gastritis.
enterol Hepatol 1993; 5 (suppl 1): S127-31.

10 Blaser MJ, Kobayashi K, Cover TL, Cao TL, Feurer ID, Perez-Perez GI. Helicobacter pylori infection in Japanese patients with adenocarcinoma of the stomach. Int $\mathcal{F}$ Cancer 1993; 55: 799-802.

11 Nomura A, Stemmerman GN, Chyou PH, Kato I, PerezPerez GI, Blaser MJ. Helicobacter pylori infection and gastric carcinoma in a population of Japanese-Americans in Hawaii. $N$ Engl $₹$ Med 1991; 325: 1132-6.

12 Parsonnet J, Friedman GD, Vandersteen DP, Chang Y, Vogelman JH, Orentreich N, et al. Helicobacter pylor infection and the risk of gastric carcinoma. $N$ Engl f Med 1991; 325: 1127-31.

13 The Eurogast Study Group. An international association between Helicobacter pylori infection and gastric cancer. Lancet 1993; 341: 1359-62. 
14 Akopyanz N, Bukanov NO, Westblom TU, Kresovich S, Berg DE. DNA diversity among clinical isolates of Helicobacter-pylori detected by PCR-based RAPD fingerprinting. Nucleic Acids Res 1992; 20: 5137-42.

15 Prewett EJ, Bickley J, Owen RJ, Pounder RE. DNA patterns of Helicobacter pylori isolated from gastric antrum, body, and duodenum. Gastroenterology 1992; 102: 829-33.

16 Blaser MJ, Perez-Perez GI, Kleanthous H, Cover TL Peek RM, Chou PH, et al. Infection with Helicobacter pylori strains possessing cag $A$ is associated with an increased risk of developing adenocarcinoma of the stomach. Cancer Res 1995; 55: 2111-5.

17 Hirai M, Azuma T, Ito S, Kato T, Kohli Y, Fujiki N. High prevalence of neutralizing activity to Helicobacter pylori cytotoxin in serum of gastric-carcinoma patients. Int $\mathcal{f}$ Cancer 1994; 56: 56-60.

18 Price AB. The Sydney System: histological division. $\mathcal{f}$ Gastroenterol Hepatol 1991; 6: 209-22.

19 Kimura K, Takemoto T. An endoscopic recognition of the atrophic border and its significance in chronic gastritis. Endoscopy 1969; 3: 87-97.

20 Kimura K. Chronological transition of the fundic-pyloric border determined by stepwise biopsy of the lesser and greater curvatures of the stomach. Gastroenterology 1972; 63: 584-92.

21 Kimura K, Satoh K, Ido K, Taniguchi Y, Takimoto T, Takemoto T. Gastritis in the Japanese stomach. Scand 7 Gastroenterol 1996; 31 (suppl 214): S17-20.

22 Kohli Y, Pfeiffer CJ, Kutty KP, Barrowman JA, Heughan C, Kepkay DL. Endoscopic diagnosis of intestinal metaplasia in Canada and Japan. F Clin Gastroenterol 1981; 3 (suppl 1): S29-33.

23 Correa P. Chronic gastritis: A clinico-pathological classification. Am ₹ Gastroenterol 1998; 83: 504-9.

24 Murakita H, Hirai M, Ito S, Azuma T, Kato T, Kohli Y. Vacuolating cytotoxin production by Helicobacter pylori isolates from peptic ulcer, atrophic gastritis and gastric carcinoma patients. Eur $\mathcal{F}$ Gastroenterol Hepatol 1994; 6 (suppl 1): S29-31.

25 Fox JG, Correa P, Taylor NS, Thompson N, Fontham E, Janney $\mathrm{F}$, et al. High prevalence and persistence of cytotoxin-positive Helicobacter pylori strains in a population with high prevalence of atrophic gastritis. $A m \mathcal{F}$ Gastroenterol 1992; 87: 1554-9.

26 Cover TL, Cao P, Lind CD, Tham KT, Blaser MJ. Correlation between vacuolating cytotoxin production by Helicobacter pylori isolates in vitro and in vivo. Infect Helicobacter pylon isolates

27 Covacci A, Censini S, Bugnoli M, Petracca R, Burroni D, Macchia G, et al. Molecular characterization of the 128-kDa immunodominant antigen of Helicobacter pylori associated with cytotoxicity and duodenal ulcer. Proc Natl Acad Sci 1993; 90: 5791-5.

28 Kohli Y, Kato T, Suzuki K, Tada T, Fujiki N. Incidence of atrophic gastritis with age in Japan and Canada. Fpn f Med 1987; 26: 158-61.

29 Hosokawa O. Clinical study of 2157 cases with early gastric cancer in the Division of Surgery, Fukui Prefectural Hospital. Fukui, Yoshidakinbundo, 1996 (in Japanese).

30 Sipponen P, Kekki M, Haapakoski J, Ihamaki T, Siurala M Gastric cancer risk in chronic atrophic gastritis: statistical calculations of cross-sectional data. Int $f$ Cancer 1985; 35: calculation

31 Correa P. Human gastric carcinogenesis: a multistep and multifactorial process-First American Cancer Society Award lecture on cancer epidemiology and prevention. Cancer Res 1992; 52: 6735-40.

32 Tummuru MKR, Cover TL, Blaser MJ. Mutation of the cytotoxin-associated cagA gene does not affect the vacuolating cytotoxin activity of Helicobacter pylori. Infect Immun 1994; 62: 2609-13.

33 Xiang Z, Censini S, Bayeli PF, Telford JL, Figura N, Rappuoli $\mathrm{R}$, et al. Analysis of expression of CagA and VacA virulence factors in 43 strains of Helicobacter pylori reveals that clinical isolates can be divided into two major types and that CagA is not necessary for expression of the types and that CagA is not necessary for expression

34 Tonokatsu Y, Hayashi T, Fukuda Y, Tamura T, ShimoyamaT. A clinico-epidemiological analysis of Helicobacter pylori $(\dot{H}$ pylori) by southern blotting with a urease gene proble. $\mathcal{F}$ Gastroenterol 1994; 29: $120-4$.

35 MegraudF, CantetF, Hua J, Birac C, Cayla R, Lamouliatte H. Molecular fingerprinting of Helicobacter pylori strains shows a low intrapatient heterogeneity. Gastroenterology 1994; 106 (suppl): A136.

36 Taylor NS, Fox JG, Akopyants NS, Berg DE, Thompson N, Shames $\mathrm{B}$, et al. Long-term colonization with single and multiple strains of Helicobacter pylori assessed by DNA fingerprinting. $f$ Clin Microbiol 1995; 33: 918-23.

37 CoverTL, TummuruMKR, CaoP, ThompsonSA, BlaserMJ. Divergence of genetic sequences for the vacuolating cytotoxin among Helicobacter pylori strains. f Biol Chem 1994; 269: 10566-73.

38 Phadnis SH, Ilver D, Janzon L, Normark S, Westblom TU. Pathological significance and molecular characterization of the vacuolating toxin gene of Helicobacter pylori. Infect Immun 1994; 62: 1557-65.

39 Atherton JC, Cao P, Peek RM, Tummuru MKR, Blaser MJ, Cover TL. Mosaicism in vacuolating cytotoxin alleles of Helicobacter pylori. F Biol Chem 1995; 30: 17771-7.

40 Schmitt W, Haas R. Genetic analysis of the Helicobacter pylori vacuolating cytotoxin: structural similarities with the IgA protease type of exported protein. Mol Microbiol 1994; 12: 307-19.

41 Blaser MJ, Chyou PH, Nomura A. Age at establishment of Helicobacter pylori infection and gastric carcinoma, gastric ulcer, and duodenal ulcer risk. Cancer Res 1995; 55: 562-5.

42 Mendall MA, Goggin PM, Molineaux N, Levy J, Toosy T, Strachan D, et al. Childhood living conditions and Helicobacter pylori seropositivity in adult life. Lancet 1992; 339: 896-7.

43 Asaka M, Kimura T, Kudo M, Takeda H, Mitani S, Miyazaki T, et al. Relationship of Helicobacter pylori to serum pepsinogens in an asymptomatic Japanese population. Gastroenterology 1992; 102: 760-6.

44 Graham DY, Malaty HM, Evans DG, Evans DJ, Klein PD, Adam E. Epidemiology of Helicobacter pylori in an asymptomatic population in the United States. Gastroenterology 1991; 100: 1495-501

45 Forman D, Webb P, Parsonnet J. Helicobacter pylori and gastric cancer. Lancet $1994 ; 343$ : $243-4$.

46 Fukuda H, Saito D, Hayashi S, Hisai H, Ono H, Yoshida S, et al. Helicobacter pylori infection, serum pepsinogen level and gastric cancer: A case-control study in Japan. $\mathscr{f} p n \mathcal{F}$ Cancer Res 1995; 86: 64-71.

47 Ching CK, Lam SK. Helicobacter pylori epidemiology in relation to peptic ulcer and gastric cancer in South and North China. F Gastroenterol Hepatol 1994; 9: S4-7.

48 Sierra R, Muñoz N, Peña AS, Biemond I, Duijn W, Lamers CBHW, et al. Antibodies to Helicobacter pylori and pepsinogen levels in children from Costa Rica: comparison of two areas with different risks for stomach cancer. Cancer Epidemiol Biomarkers Prev 1992; 1: 449-54.

49 Palli D, Decarli A, Cipriani F, Sitas F, Forman D, Amdori D, et al. Helicobacter pylori antibodies in areas of Italy at varying gastric cancer risk. Cancer Epidemiol Biomarkers Prev 1993; 2: 37-40.

50 Crabtree JE, Taylor JD, Wyatt II, Heatly RV, Shallcross TM, Tompkins DS, et al. Mucosal IgA recognition of Tompkins DS, et al. Mucosal IgA recognition of Helicobacter pylori $120 \mathrm{kDa}$ protein, peptic ulce

51 Schlemper RJ, Werf SDJ, Vandenbroucke JP, Biemond I, Lamers CBHW. Seroepidemiology of gastritis in Japanese and Dutch working populations: evidence for the development of atrophic gastritis that is not related to Helicobacter pylori. Gut 1995; 37: 199-204.

52 Azuma T, Konishi J, Tanaka Y, Hirai $M$, Ito $S$, Kato $T$, et al. Contribution of HLA-DQA gene to host's response against Helicobacter pylori. Lancet 1994; 343: 542-3.

53 Beales ILP, Davey NJ, Pusey CD, Lechler RI, Calam J. Long-term sequelae of Helicobacter pylori gastritis. Lancet 1995; 346: 381-2.

54 Boren T, Falk P, Roth KA, Larson G, Normark S. Attachment of Helicobacter pylori to human gastric epithelium ment of Helicobacter pylon to human gastric epithelium 1892-5. 